\title{
Use of statistical simulation in construction planning
}

\author{
Tatyana Rogovenko ${ }^{1}$, Marina Zaitseva ${ }^{1, *}$ \\ ${ }^{1}$ Don State Technical University, pl. Gagarina, 1, Rostov-on-Don, 344010, Russia
}

\begin{abstract}
In this paper, the researchers propose taking into account construction equipment recovery time to estimate the time consumption of construction and installation works. Post-failure recovery time can be modeled using Monte-Carlo simulation. Statistical simulation is used to create a general population of machine parts by means of intermediate subpopulation. The population is made of smaller samples by creating an intermediate subpopulation using distributions of order statistics; the method is referred to as FISP method.
\end{abstract}

\section{Introduction}

When planning construction works, in particular when creating a network diagram, one has to take into account many external factors affecting the process. The effect of external uncertainty and risk factors necessitates the use of special methods by planners. Unexpected equipment failures due to faulty design, aging, or fatigue can be taken into account when planning the deadlines, if the planner uses state-of-the-art methods to estimate the reliability of machines [1-3]. One of such possible reliability parameters to be considered is the machine recovery time. The recovery time is a random variable that usually has exponential distribution, e.g. Weibull's. Planning specialists (planners) often have to rely on limited data i.e. small statistical samples. Thus, when it comes to estimations, a transition from small samples to a whole general population of machines (a finite general population, FGP), that may consist of $10^{4}$ or more units, is always a relevant problem. Given such limited initial data, the Monte Carlo method combined with other statistical methods may work [4-11].

\section{Statement of Problem}

The average expected time to complete the works depends on the post-failure recovery time of the machine. The most probable time to complete $T_{A}(P)$, as specified for normal conditions $T_{N E}$, is adjustable by adding construction machinery recovery time $T_{R}$ with a given probability $P$ :

$$
T_{A}(P)=T_{N E}+T_{R}(P)
$$

*Corresponding author: marincha1@rambler.ru 
Assume that the recovery time $T_{R}$ is distributed per the Weibull law [12]:

$$
F\left(T_{R}\right)=1-\exp \left(-\left(\frac{T_{R}-c_{S}}{a_{S}}\right)^{b_{S}}\right)
$$

where $a_{S}, b_{S}, c_{S}$ - is a sample of scale, form, and shift parameters, assessed.

Then an estimate based on selected data will look like:

$$
T_{R S}(F)=c_{S}+a_{S} \sqrt[b S]{-\ln (1-F)}
$$

The general population estimates will look like:

$$
T_{R G}(F)=c_{G}+a_{G} \sqrt[b_{G}]{-\ln (1-F)}
$$

The problem is to evaluate the Weibull distribution with parameters $a_{G}, b_{G}, c_{G}$ for the FGP as well as to calculate $T_{R G}(P)$ for a given probability $P$. This problem can be solved by statistical simulation and correlations obtained in [4].

\section{FISP method}

The FISP method is essentially about sequential simulation of finite intermediate subpopulations (FISP) $N_{T}=10^{2}-10^{4}$ using small samples of size $n_{S}=5-15$, which is followed by modeling the finite general population (FGP) $N_{G}=10^{4}-10^{6}$ using the correlative dependencies obtained in [4], see Fig. 1.

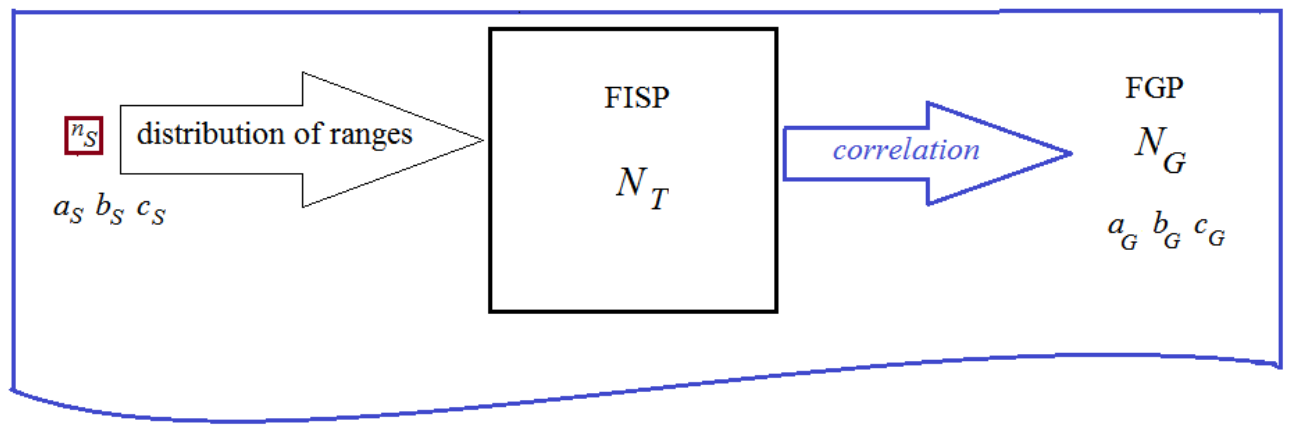

Fig. 1. Transition from small samples to the general population using the FISP method

For such simulation, FISPs are determined by the number of additional values of random variable $m_{a d}$ based on the distribution law and depending on the extent of order statistics $R_{i i+1}=x_{i+1}-x_{i}$ as well as their distribution law:

$$
m_{a d}=\sum_{i=0}^{n_{S}}\left(n_{a d_{i}}+\Delta_{i}\right)
$$

where the components are calculated using the formula: 


$$
\begin{gathered}
n_{a d_{0}}=\left[\frac{F^{*} \cdot\left(N_{T}-n_{S}-2\right)}{\left(x_{1}-A\right) \cdot \sum_{j=1}^{n_{S}-1}\left(\left(F\left(R_{j+1}\right)+F^{*}+F^{* *}\right) / R_{j_{j+1}}\right)}\right] \\
\left.n_{a d_{i}}=\left[\frac{F\left(R_{i i+1}\right) \cdot\left(N_{T}-n_{S}-2\right)}{R_{i i+1} \cdot \sum_{j=1}^{n_{S}^{-1}}\left(\left(F\left(R_{j_{j+1}}\right)+F^{*}+F^{* *}\right) / R_{j+1}\right)}\right]\right) \text { for } \mathrm{i}=1, \ldots, \mathrm{nS}-1 \\
n_{a d_{n}}=\left[\frac{F^{* *}\left(N_{T}-n_{S}-2\right)}{\left(B-x_{n_{S}}\right) \cdot\left(\sum_{j=1}^{n_{S}-1}\left(\left(F\left(R_{j_{j+1}}\right)+F^{*}+F^{* *}\right) / R_{j j+1}\right)\right.}\right] \\
F^{*}=\min _{1 \leq i \leq n_{S}-1}\left\{\frac{F\left(R_{i_{i+1}}\right) \cdot\left(x_{1}-A\right)}{R_{i_{i+1}}}\right\} \\
F^{* *}=\max _{1 \leq i \leq n_{S}-1}\left\{\frac{F\left(R_{i_{i+1}}\right) \cdot\left(B-x_{n_{S}}\right)}{R_{i_{i+1}}}\right\}
\end{gathered}
$$

where $F\left(R_{i i+1}\right)$ - distribution of order statistics:

$$
F\left(R_{i i+1}\right)=\frac{n_{S} !}{(i-1) !\left(n_{S}-i+1\right) !} \int_{0}^{R_{i i+l}} \int_{A}^{c_{S}-R r s} P^{i-1}(x) p(x) p\left(x+R_{i i+1}\right)\left[1-P\left(x+R_{i i+1}\right)\right]^{n_{S}-i+1} d x d R
$$

$P(x), p(x)$ are the probability function and density, $A$ and $B$ are the limits of the simulated range.

The value of $\Delta_{\mathrm{i}}$ is determined by successive approximations so that $N_{T}=n_{s}+m_{a d}+2$. If the order statistics are equal, the measurement error of the random variable is assumed as the extent value for simulating the additional values.

When debugging the FISP method, the homogeneity of the source population and the FISP was evaluated using the Wilcoxon test; the Smirnov-Kolmogorov test was used to verify the hypothesis that the distribution functions of the general populations the samples were taken from coincide in the entire domain. Table 1 lists the share of FISPs $N_{W}$ that are Wilcoxon-homogeneous to the initial population for a significance of $\alpha=0.01$; the share of FISPs $N_{K}$ that share the general population with the source population (based on the Smirnov-Kolmogorov test for a significance of $\alpha=0.01 ; 0.001$.

Table 1. Share of FISPs that pass the tests

\begin{tabular}{|c|c|c|c|}
\hline$n_{S}$ & $\begin{array}{c}N_{W}, \% \\
\text { for } \alpha=0.01\end{array}$ & $\begin{array}{c}N_{K}, \% \\
\text { for } \alpha=0.01\end{array}$ & $\begin{array}{c}N_{K}, \% \\
\text { for } \alpha=0.001\end{array}$ \\
\hline 5 & 69 & 79 & 88 \\
\hline 10 & 72 & 80 & 88 \\
\hline 15 & 74 & 78 & 84 \\
\hline
\end{tabular}


The FISP simulation algorithm was implemented in FISP method as a part of the MRM software suit developed by the Motor Vehicles, Construction and Road Machines Department, Don State Technical University, to study the problems of machine reliability, see Fig. 2.

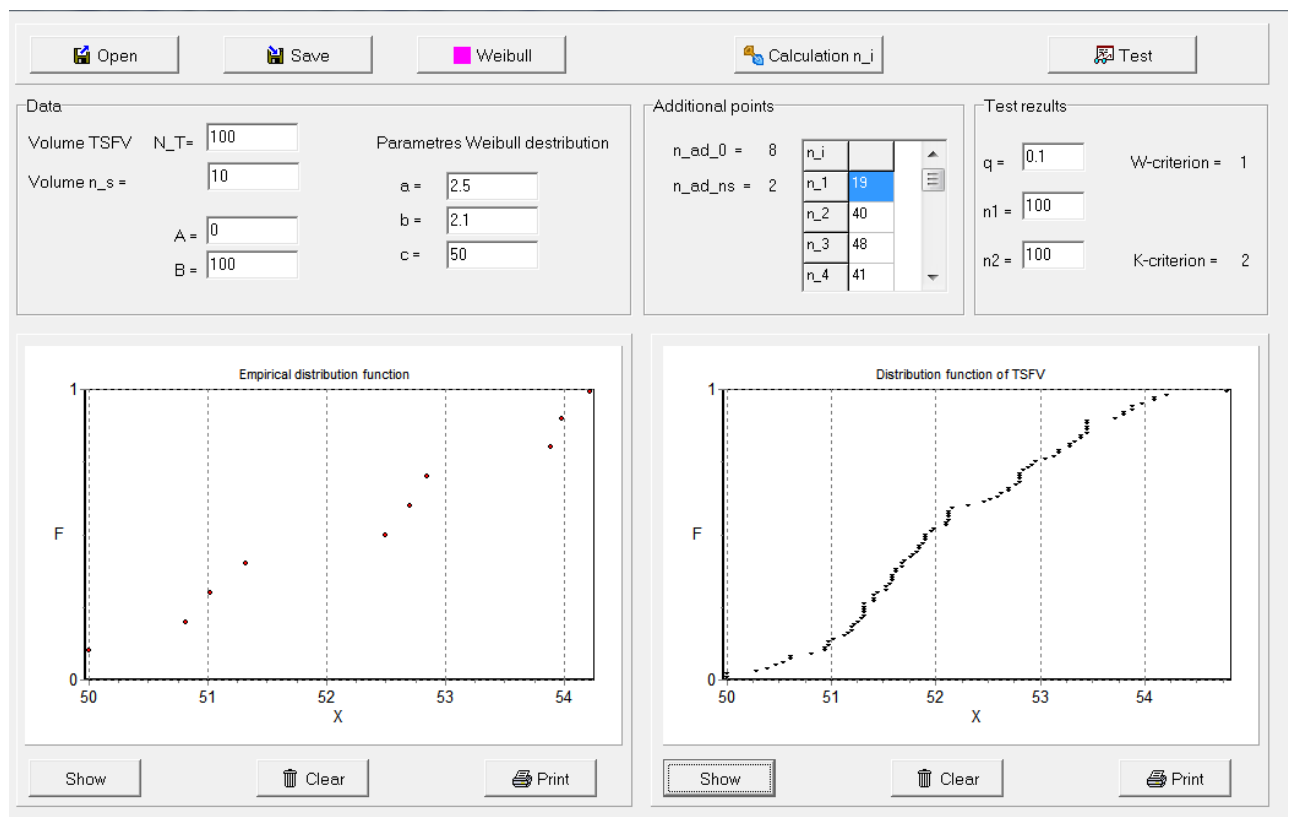

Fig. 2. FISP method window

\section{Application}

As an example, we've analyzed a sample of recovery time $T_{R}$ values; the sample of size $n_{S}=10$ had a Weibull distribution with the following parameters: $a_{S}=2.14 ; b_{S}=3.04 ; c_{\mathrm{S}}=1.2$. The FISP method helped determine the parameters of an FGP with recovery time $T_{R}$ : $a_{G}=3.1 ; b_{G}=4.3 ; c_{G}=0.92$ for a sample size $N_{G}=10^{4}$ using an FISP of size $N_{T}=10^{2}$. FISP simulation is carried out $\left[N_{T} / n_{S}\right]$ times to obtain stable statistics. One of the simulation scenarios is shown in Fig. 3. 


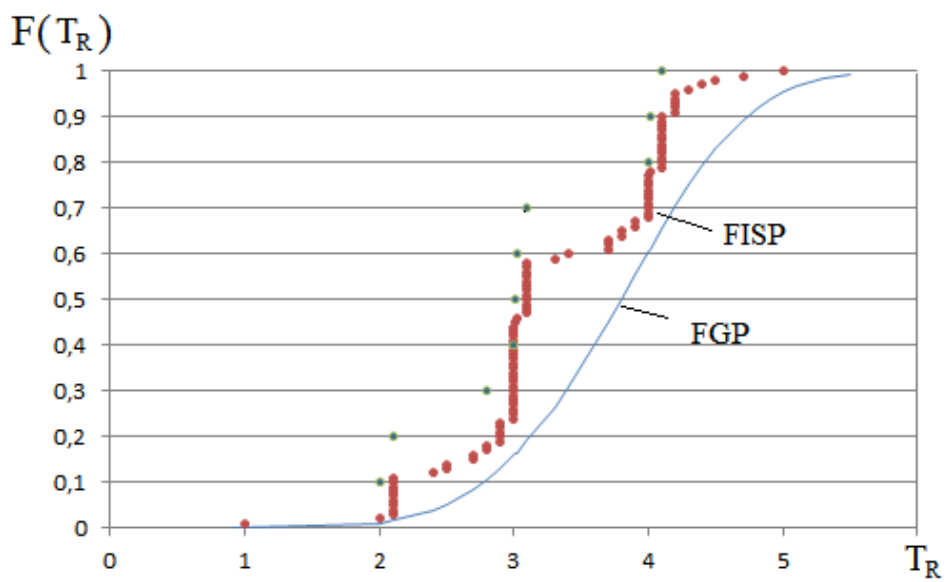

Fig. 3. Distribution of FGP recovery time as a result of simulation for $N_{G}=10^{4}$.

FGP simulation using the FISP method enables determination of $T_{R}$ values for the empirical $T_{R S}(P)$ distribution function and FGP $T_{R G}(P)$ distribution for various $P$ values. Table 2 contains the results of such simulation.

Table 2. Recovery time $T_{R}$ for various $P$ values

\begin{tabular}{|c|c|c|c|}
\hline $\mathrm{T}_{\mathrm{R}}(\mathrm{P})$ & $\mathrm{P}=0.5$ & $\mathrm{P}=0.9$ & $\mathrm{P}=0.99$ \\
\hline $\mathrm{T}_{\mathrm{RS}}(\mathrm{P})$ & 3,1 & 4,1 & 4,1 \\
\hline $\mathrm{T}_{\mathrm{RG}}(\mathrm{P})$ & 3,8 & 4,8 & 5,6 \\
\hline
\end{tabular}

The most probable time to complete $T_{A}(P)$, as specified for normal conditions $T_{N E}$, is adjustable by adding construction machinery recovery time $T_{R}$ with a given probability. When FGP results are used to determine the most probable time to complete the works $T_{A}(P)$, the resulting value is $22-37 \%$ larger compared to using small samples.

\section{Conclusions}

The most probable time to complete the works can be calculated using statistical simulation based on the construction equipment reliability parameters. The FISP method combines the Monte Carlo method, order statistics distribution, and correlation for a more accurate transition from small samples to the finite general population; it has been successfully developed and can be used in construction planning to estimate the most probable time to complete the works.

\section{References}

1. M. Krzemiński, MATEC Web of Conferences, 86, 05002 (2016)

2. I. I. Vainshtein, G. E. Mihalchenko, J. V. Vainshtein, K. V. , Vestnik SibGAU, 16, $645-650(2015)$ 
3. V.I. Vainshtein, I.I.Vainshtein, G. E. Mikhal'chenko, J. Mach. Man. and Rel., 44, 79$83(2015)$

4. V. E. Kas'yanov, T.N. Rogovenko, I. V. Topilin, Rus. Eng. Res., 3, 9-11 (2003)

5. P. Brandimarte, Introduction to Monte Carlo Methods, Handbook In Monte Carlo Simulation (2014)

6. A. Goldfeld, A. Dubi, Qual. And Rel. Eng. Int., 3 (1987)

7. C. P. Robert, Monte Carlo Methods (2016)

8. V. E. Kas'yanov, T.N. Rogovenko, M M Zaitseva, Bul. of Rost. St. Trans. Un., 1, 16-20 (2010)

9. V. E. Kas'yanov, T.N. Rogovenko, M M Zaitseva, Bul. of the Don St. Tech. Un., 1, 91 94 (2010).

10. M. M. Zaitseva, Obespecheniye zadannogo ustalostnogo pesursa detaley odnokovshovogo excavatora s ispolzovaniem malyh viborok (2010)

11. M. M. Zaitseva, Obespecheniye nadeznosti detaley mashin (2012)

12. H. Rinne, The Weibull Distribution (2008) 